\title{
JEJUNOGASTRIC INTUSUSCEPTION: RARE COMPLICATION OF GASTROJEJUNOSTOMY
}

Bhupesh Tirpude ${ }^{1}$, Hemant Bhanarkar²

\section{HOW TO CITE THIS ARTICLE:}

Bhupesh Tirpude, Hemant Bhanarkar. "Jejunogastric Intususception: Rare Complication of Gastrojejunostomy". Journal of Evolution of Medical and Dental Sciences 2014; Vol. 3, Issue 34, August 11; Page: 8996-9000, DOI: $10.14260 /$ jemds/2014/3158

\begin{abstract}
Jejunogastricintussusception through a gastrojejunostomy stoma is one of the rarest complications of the previous gastric surgery. The incidence is reported to be less than $0.1 \%$. An elderly male presented to the hospital with h/o vomiting, pain in abdomen since 10 days. The patient was undergone upper G I Scopy and CT scan abdomen as a suspected c/o carcinoma stomach. A primarily healed midline scar from the previous surgery for large duodenal perforation. On exploration it was found that there was a mass in the stomach, which on gastrotomy revealed gangrenous jejunal loops herniated through previous stoma. Gangrenous jejunum was resected and Billroth II was done.
\end{abstract}

KEYWORDS: Jejunogastric, intussuception, gangrenous, gastrojejunostomy.

INTRODUCTION: Jejunogastric intussusception (JGI) is a rare complication of gastrectomy with an incidence of $0.1 \%$. It usually presents with severe epigastric pain, vomiting, and hematemesis. A history of gastric surgery can help in making an accurate and early diagnosis, which calls forth an urgent surgical intervention. Only reduction or resection with revision of the previously performed anastomosis is the choice which is decided according to the operative findings.

We present a case of JGI in a patient with a history of operation for large duodenal perforation 6 yrs back. At emergent laparotomy, an efferent loop Jejunogastricintussuception was found. Due to necrosis, resection of the intussuscepted bowel with Roux-en-Y anastomosis was performed. Postoperative recovery was uneventful.

A mortality rate of $10 \%$ and even as high as of $50 \%$ has been reported if surgical intervention has been delayed, [5, 6] therefore, early diagnosis of this condition is mandatory. Although a history of gastric surgery may help in making such a diagnosis, preoperative awareness of this condition has been reported to be difficult in most of the cases.

CASE HISTORY: A 60yrs old male patient came to hospital with c/o of pain in abdomen, vomiting, lump in abdomen since 15 days. Patient was undergone upper G I scopy with biopsy and CECT scan abdomen in private hospital as a case of carcinoma stomach. On general patient was dehydrated with pulse $120 / \mathrm{min}$, febrile, and Ryles tube contain hemorrhagic aspiration.

On local examination, there was the upper midline scar of previous surgery with mass palpable at epigastrium, mobile, firm in consistency. Margins were ill defined. Biopsy report was s/o of necrotic tissue with inflammatory cells. The patient was a known case of acid peptic disease and chronic smoker. The patient was operated for peptic ulcer perforation 6yr back (closure of perforation \& gastro jejunostomy was done).

CECT scan abdomen was s/o large necrotic mass arising from the greater curvature with perigastric lymphadenopathy [Fig. 1]. 
The rapid acute evaluation asked for the urgent laparotomy that emphasized: soft tumourmass, intragastrically mobile without any scar at the stomach or duodenum level; adherent to the posterior wall of the stomach, we were discovered a ball of jejunal loops that couldn't be undone [Fig. No. 2]. The anterior gastrotomy was sets the diagnosis: jejunogastricintusuception of the efferent loops through gastro jejunostomy stoma [Fig. No. 3 \& 4]. The loops of jejunum were completely gangrenous. Resection anastomosis with Billroth's II was done. Post operative period wasuneventfull. Oral started on 5th post op day and suture removed on 9th post op day.

DISCUSSION: The term retrograde intussusception (invagination) was first introduced by John Hunter to define an invagination of the intussusceptum in an antiperistaltic or a proximal direction as opposed to the usual peristaltic or distal direction. ${ }^{[7]}$ Intussusception is an uncommon condition that may arise at any age. It is usually seen in childhood, and only $5 \%$ of cases occur in adults. [8]

Jejunogastric intussusception is a rare complication sofgastrojejunostomy, Billroth II gastrectomy, and Roux-en-Y anastomosis. There were less than 200 published cases since its first description in 1914 by Bozzi in a patient with gastrojejunostomy. [3] In 1922, Lundberg reported a case of JGI in a patient with a history of Billroth II resection. [4]

According to the type of intussuscepted loop, JGI is classified into three types: type I, antegrade or afferent loop intussusception; type II, retrograde or efferent loop intussusception; and type III, combined form. [5] Efferent loop JGI is seen in $80 \%$ of the cases as in the present case, while others account for the remaining 20\%. [5]

The exact mechanism of the JGI is still not well understood. Long afferent loop, jejunal spasm with abnormal motility, increased mobility of the efferent loop, and adhesions leading to the intussusception of more mobile segment into a fixed segment may be the underlying causes. ${ }^{[1]}$ It is also postulated that increased intra-abdominal pressure, a dilated atonic stomach especially after vagotomy, and retrograde peristalsis may be responsible for the development of JGI.[1]

Two different forms of JGI have been described according to its clinical presentation.[9] In the acute form, incarceration and strangulation of the intussuscepted loop causing acute severe epigastric pain, vomiting, and subsequently, hematemesis generally occur. However, spontaneous reduction is usual in the chronic type. A palpable abdominal mass can be observed in almost half of the cases. [1,10] Therefore, carefully taken history with a good physical examination helps to suspect this rare condition.

Early diagnosis of the acute form is of paramount importance. The first specific diagnostic study should be an emergency endoscopy, which is carried out by endoscopists aware of JGI and its endoscopic picture. Computed tomography allows the differentiation of the distinct stages of the disease. It shows a dilated stomach with an intragastric filling by the bowel loops. In spite of the endoscopic and imaging findings, most reported cases of JGI were diagnosed at surgery. [9]

Surgical options include only reduction or resection of the compromised bowel with the revision of the anastomosis depending on the conditions found during the operation. [6] It could not be possible to prevent necrosis in the intussuscepted jejunal bowel despite early diagnosis and immediate surgical intervention. Therefore, resection with revision of the previous anastomosis can be the most appropriate surgical method, in a patient with acute JGI. 
CONCLUSIONS: JGI is a rare life-threatening complication of gastric surgery, which is often diagnosed at surgery. It should be kept in mind that a sudden onset of epigastric pain, vomiting and subsequent hematemesis, and a palpable epigastric mass in a patient with a previous gastric surgery can be important diagnostic clues for JGI. Early surgical intervention is the most important factor for prevention of morbidity and mortality.

\section{REFERENCES:}

1. Waits J. O., Beart Jr. R. W., and Charboneau J. W., "Jejunogastric intussusception," Archives of Surgery, vol. 115, no. 12, pp. 1449-1452, 1980. View at Scopus.

2. Conklin E. F. and Markowitz A. M., "Intussusception, a complication of gastric surgery," Surgery, vol. 57, no. 3, pp. 480-488, 1965. View at Scopus.

3. Bozzi E., "Annotation,” Bulletin of Academy of Medicine, vol. 122, pp. 3-4, 1914.

4. Lundberg S. , "Retrograde Dunndarm invagination nach Gastroenterostomie," Acta Chirurgica Scandinavica, vol. 54, pp. 423-433, 1922.

5. Shackman R., "Jejunogastric intussusception," British Journal of Surgery, vol. 27, pp. 475-480, 1940.

6. Sibley W. L. "Chronic intermittent intussusception through the stoma of a previous gastroenterostomy," Proceedings of the Staff Meetings. Mayo Clinic, vol. 9, pp. 364-365, 1934.

7. Mason L. B., "Retrograde jejunogastric intussusception following gastrectomy," Archives of Surgery, vol. 81, pp. 485-491, 1960. View at Scopus.

8. Dawes L. C., Hunt R., Wong J. K., and Begg S., "Multiplanar reconstruction in adult intussusception: case report and literature review," Australasian Radiology, vol. 48, no. 1, pp. 74-76, 2004. View at Publisher • View at Google Scholar • View at Scopus.

9. Tokue H. and Tsushima Y., "Jejunogastric intussusception: life-threatening complication occuring 55 years after gastrojejunostomy," Internal Medicine, vol. 48, no. 18, pp. 1657-1660, 2009. View at Publisher • View at Google Scholar • View at Scopus.

10. Foster D. G., "Retrograde jejunogastric intussusception-a rare cause of hematemesis," AMA Archives of Surgery, vol. 73, pp. 1009-1017, 1956.
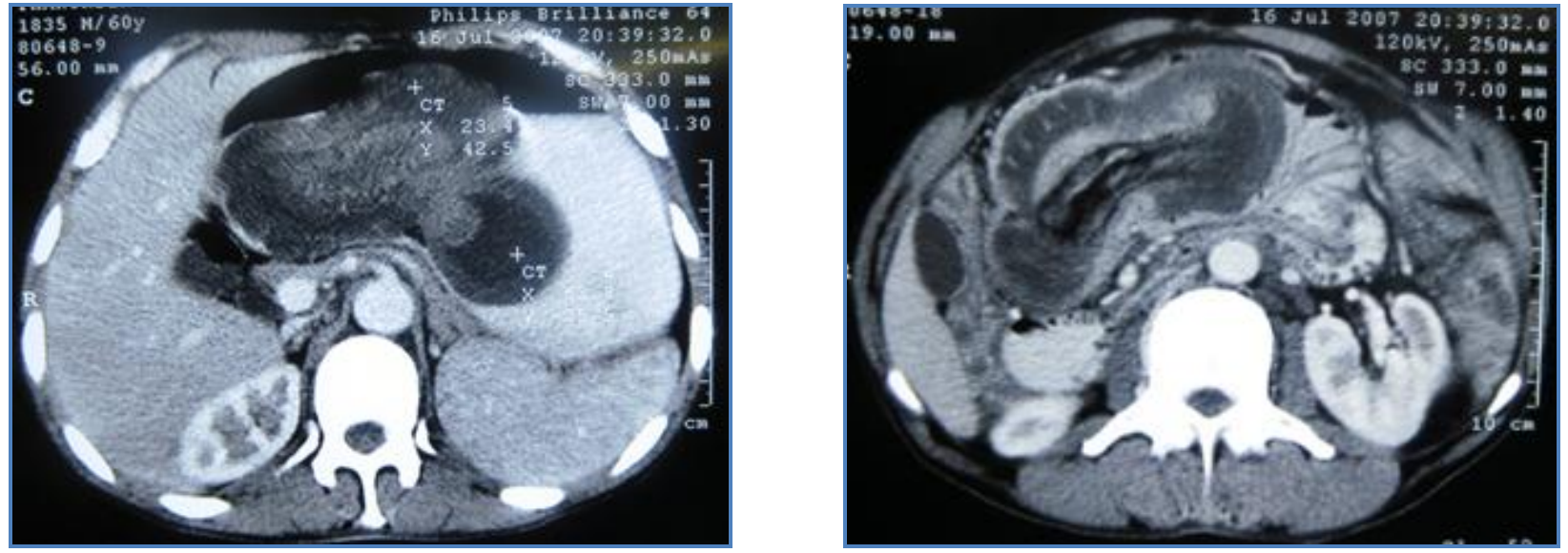

Fig. No. 1: CECT Abdomen s/o large mass arising from greater curvature 


\section{CASE REPORT}

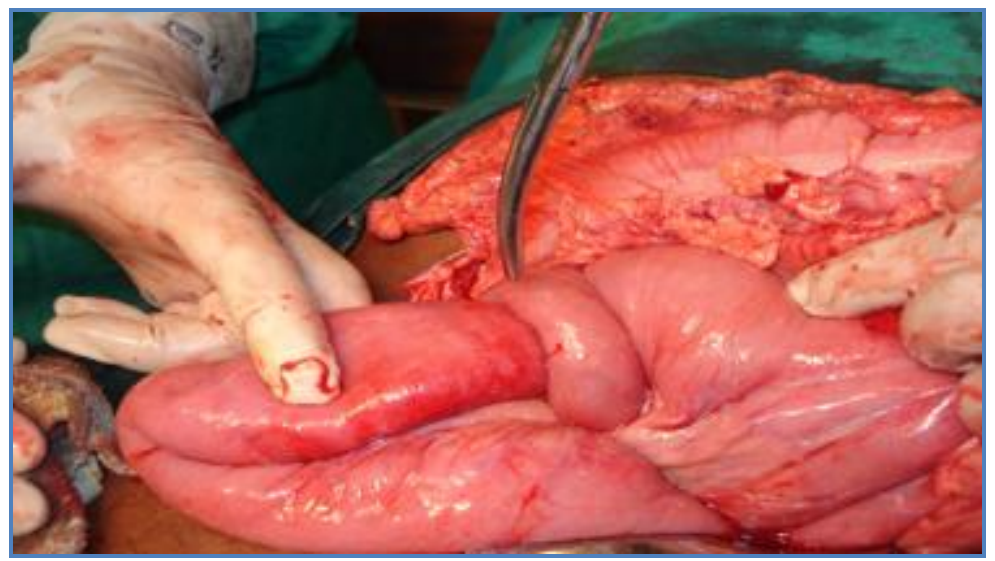

Fig. No. 2: Jejunal loop intusuception through posterior wall of stomach

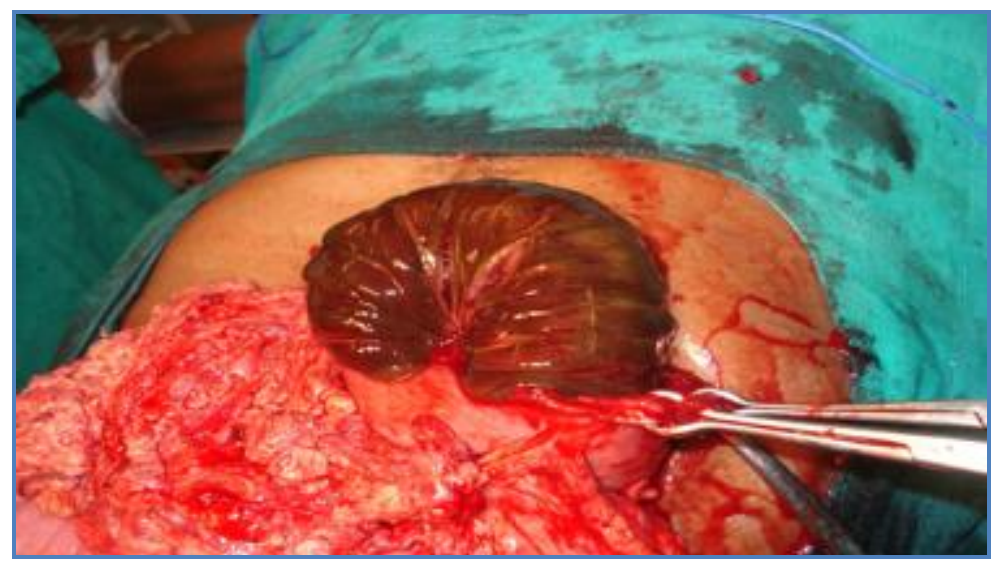

Fig. No. 3: Anterior` gastrotomy shows gangrenous jejunal loops

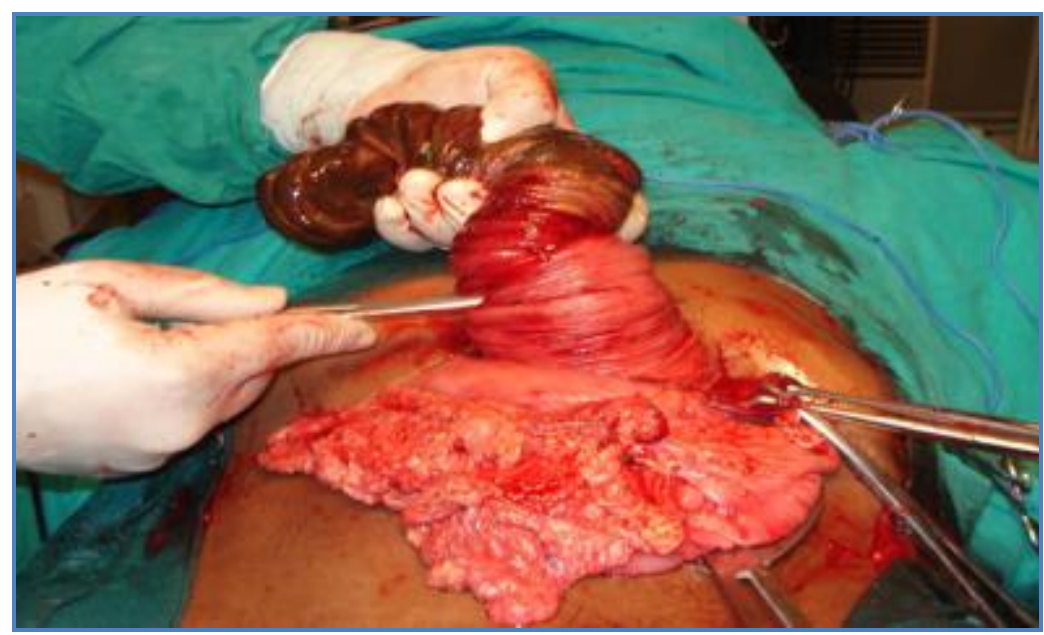

Fig. No. 4: Intussuscepted gangrenous jejunal loop 


\section{CASE REPORT}

\section{AUTHORS:}

1. Bhupesh Tirpude

2. Hemant Bhanarkar

\section{PARTICULARS OF CONTRIBUTORS:}

1. Associate Professor, Department of Surgery, Indira Gandhi Government Medical College, Nagpur.

2. Assistant Professor, Department of Surgery, Indira Gandhi Government Medical College, Nagpur

\section{NAME ADDRESS EMAIL ID OF THE} CORRESPONDING AUTHOR:

Dr. Bhupesh Tirpude,

302-C Wing, Majestic Height,

Hill Road, Shivaji Nagar,

Nagpur-440010.

Email: btirpude@gmail.com

Date of Submission: 24/07/2014.

Date of Peer Review: 25/07/2014.

Date of Acceptance: 05/08/2014.

Date of Publishing: 08/08/2014. 